\title{
PROPAGATION OF OPTICAL FEMTOSECOND PULSES THROUGH QUARTZ AND GLASS BK-7
}

\author{
V.P. Leshchenko, A.I. Povrozin, G.V. Sotnikov, A.V. Vasiliev, K.V. Galaydych, S.Yu. Karelin \\ National Science Center "Kharkov Institute of Physics and Technology”, Kharkiv, Ukraine \\ E-mail:pai40@kipt.kharkov.ua
}

In the approximation of dispersion theory to the fourth order inclusive, a theoretical study of the propagation of optical femtosecond pulses of a Gaussian profile and a profile proportional to the hyperbolic secant through quartz and BK-7 glass was carried out. Based on the solutions of the equations for the propagation of pulses of various initial durations through optical materials, dependencies "material length - pulse duration" are obtained. It is shown that, compared with the second approximation of dispersion theory, the fourth approximation gives a slightly lengthy pulse duration. Peculiarities of various time pulse profiles on the pulses duration are also shown. Analytical consideration is confirmed by numerical calculations.

PACS: 42.55.Ah

\section{INTRODUCTION}

The design and development of new laser systems with ultrahigh power values and ultra-short pulse durations have required the consideration of a number of problems related to the theory of dispersion and that are directly related not only to such systems, but also have independent interest [1 - 3]. Such tasks include, in particular, the study of the dispersion properties of various materials used in the elements of the aforementioned systems, fiber optics, the developed systems of laser acceleration of charged particles, and other branches of physics and technology.

Dispersion properties determine the parameters of the propagation of short laser pulses through such materials. In existing publications on this subject, not all aspects of dispersion have received sufficient coverage. The drawback of these works (see, for example, [4]) is the consideration of only the second order of optical materials dispersion when short pulses of a Gaussian profile pass through them. Such simplifications do not allow a sufficiently complete idea about the parameters of such pulses after passing through these materials. Femtosecond laser pulses can have a time profile of the field amplitude proportional to the hyperbolic secant [5]. The propagation of such pulses through optical materials has not been studied. In the process of developing a system of laser acceleration of electrons, conducted at IPENMU NSC KIPT, it became necessary to determine the parameters of femtosecond pulses after passing them through its elements of a given length. The results of these studies are presented below.

\section{BASIC EQUATIONS}

The equation of propagation of an optical femtosecond pulse (hereinafter referred to as the "pulse") in the second approximation of dispersion theory has the form [6]:

$$
\left(\frac{\partial}{\partial z}-i \frac{k_{2}}{2} \frac{\partial^{2}}{\partial t^{2}}\right) A(z, t)=0,
$$

where $A(z, t)$ is the complex amplitude of the pulse in the traveling coordinate system $(z, t), z$ is the coordinate in the pulse direction, retarding time $t=t_{1}-z / u$, $t_{1}$ is time, $u$ is the group velocity of the wave packet, $k_{2}=\left(\frac{\partial^{2} k}{\partial \omega^{2}}\right)$ is the dispersion parameter of the group velocity of the wave packet, $k(\omega)=\omega n(\omega) / c$ is the wave vector, the center frequency of the wave packet, $\mathrm{c}$ is the light speed in vacuum, $n(\omega)$ is the refractive index of the optical material as a function of frequency.

The propagation equation in the fourth approximation of the theory of dispersion has the form [7]:

$$
\left(\frac{\partial}{\partial z}-\frac{i}{2} k_{2} \frac{\partial^{2}}{\partial t^{2}}-\frac{k_{3}}{6} \frac{\partial^{3}}{\partial t^{3}}+\frac{i}{24} k_{4} \frac{\partial^{4}}{\partial t^{4}}\right) A(z, t)=0,
$$

where

$$
\begin{gathered}
k_{3}=\frac{\partial^{3} k}{\partial \omega^{3}}+\frac{3}{k} \frac{\partial^{2} k}{\partial \omega^{2}} \frac{\partial k}{\partial \omega} \\
k_{4}=\frac{\partial^{4} k}{\partial \omega^{4}}+\frac{4}{k} \frac{\partial^{3} k}{\partial \omega^{3}} \frac{\partial k}{\partial \omega}+\frac{3}{k}\left(\frac{\partial^{2} k}{\partial \omega^{2}}\right)^{2} .
\end{gathered}
$$

The values of the wave vector $\mathrm{k}$ and its derivatives are calculated at a frequency $\omega_{0}$.

\section{SOLUTIONS OF THE BASIC EQUATIONS}

The equations in the second and fourth approximations of the dispersion theory are solved for pulses with two initial time profiles of the field amplitude. The initial Gaussian profile in the traveling coordinate system has the form:

$$
A(t)=A_{0} \exp \left(-\frac{2 \ell n 2}{\tau_{0}^{2}} t^{2}\right)
$$

The initial profile proportional to the hyperbolic secant in the traveling coordinate system has the form:

$$
A(t)=A_{0} \operatorname{Sech} \frac{1,76 t}{\tau_{0}} .
$$

In formulas (5) and (6), $A_{0}$ is the maximum amplitude, $\tau_{0}$ is the pulse duration at half the maximum intensity.

The solution of equation (1) for a pulse with a Gaussian profile (hereinafter, we omit the word "initial") has the form:

$$
A\left(t, \Phi_{2}\right)=\frac{A_{0}}{\sqrt{V}} \exp \left(-\frac{2 \ell n 2}{\tau_{0}^{2} V^{2}} t^{2}+i \varphi\right)
$$


where the coefficient of temporal extension of the pulse $V$ and the phase $\varphi$ of the complex amplitude of the pulse are:

$$
\begin{gathered}
V=\sqrt{1+\left(\frac{4 \ln 2}{\tau_{0}^{2}} \Phi_{2}\right)^{2}}, \\
\varphi=\frac{8(\ln 2)^{2}}{\tau_{0}^{4} V^{2}} \Phi_{2} t^{2}-\frac{1}{2} \operatorname{arctg}\left(\frac{4 \ln 2}{\tau_{0}^{2}} \Phi_{2}\right) .
\end{gathered}
$$

In eqs. (8), (9) the second derivative in frequency $\omega$ of the phase shift $\Phi_{2}$ has the form:

$$
\Phi_{2}=k_{2} \ell,
$$

where $\ell$ is the length of the optical material.

For an impulse with a profile proportional to the hyperbolic secant, the solution of equation (1) has the form:

$$
A\left(t, \Phi_{2}\right)=A_{0} \int_{-\infty}^{\infty} \frac{\exp \left[\frac{i\left(t-t_{1}\right)^{2}}{2 \Phi_{2}}\right]}{\sqrt{2 \pi i \Phi_{2}}} \operatorname{Sech} \frac{1.76 t_{1}}{\tau_{0}} d t_{1} .
$$

The solution of equation (2) for a pulse with any amplitude profile has the form:

$$
\begin{aligned}
& A\left(t, \Phi, \Phi_{1}, \Phi_{2}, \Phi_{3}, \Phi_{4}\right)=\frac{1}{2 \pi} \int_{-\infty}^{\infty} A(\omega) \exp \left\{-i\left[\frac{\Phi_{2} \omega^{2}}{2}-\frac{1}{6}\right.\right. \\
& \left.\left.\left(\Phi_{3}+\frac{3 \Phi_{1} \Phi_{2}}{\Phi}\right) \omega+\frac{1}{24}\left(\Phi_{4}+\frac{4 \Phi_{1} \Phi_{3}}{\Phi}+\frac{3 \Phi_{2}^{2}}{\Phi}\right) \omega^{3}+\omega t\right]\right\} d \omega,
\end{aligned}
$$

where $A(\omega)$ - is the Fourier transform of the profile of the pulse amplitude, $\Phi=2 \pi n(\lambda) \ell / \lambda$ is the phase shift when the pulse passes through an optical material long $\ell$, and its frequency derivatives $\Phi_{1}, \Phi_{2}, \Phi_{3}, \Phi_{4}$ in the wavelength scale have the form [1]:

$$
\begin{gathered}
\Phi_{1}=\left(n-\lambda \frac{\partial n}{\partial \lambda}\right) \ell / c, \Phi_{2}=\frac{\lambda^{3} \ell}{2 \pi c^{2}} \cdot \frac{\partial^{2} n}{\partial \lambda^{2}}, \\
\Phi_{3}=-\frac{\lambda^{4} \ell}{6 \pi^{2} c^{3}}\left(3 \frac{\partial^{2} n}{\partial \lambda^{2}}+\lambda \frac{\partial^{3} n}{\partial \lambda^{3}}\right), \\
\Phi_{4}=\frac{\lambda^{5} \ell}{24 \pi^{3} c^{4}}\left(12 \frac{\partial^{2} n}{\partial \lambda^{2}}+8 \lambda \frac{\partial^{3} n}{\partial \lambda^{3}}+\lambda^{2} \frac{\partial^{4} n}{\partial \lambda^{4}}\right),
\end{gathered}
$$

where $n(\lambda)$ is the refractive index of the optical material, which, like its derivatives, is calculated at the central wavelength of the wave packet, and , $c$ is the speed of light in vacuum. The refractive indices and their derivatives for quartz and BK-7 glass are found from the Selmeier formula for an central wavelength of a wave packet of $800 \mathrm{~nm}$. It has the form [4]:

$$
n=\sqrt{1+\sum_{i=1}^{3} \frac{\lambda^{2} B_{i}}{\lambda^{2}-C_{i}}} .
$$

The values of the constants $B_{i}$ and $C_{i}$ are given in Tables 1, 2 .

The elongation of pulses with a Gaussian profile in the second approximation of the dispersion theory was calculated by formula (8), the duration of pulses with a profile proportional to the hyperbolic secant in the same approximation of dispersion theory was determined by the integral (11). The duration of pulses with both profiles was determined by the integral (12). The calculation results are presented in Tables 3-6 and in Figs. 1-4.

Table 1

Selmeier coefficients $B_{i}$ in the dispersion formula (16)

\begin{tabular}{|l|l|c|c|}
\hline $\begin{array}{c}\text { Optical } \\
\text { material }\end{array}$ & $\mathrm{B}_{1}$ & $\mathrm{~B}_{2}$ & $\mathrm{~B}_{3}$ \\
\hline Quartz & $6.691225 \cdot 10^{-1}$ & $4.345839 \cdot 10^{-1}$ & $8.716917 \cdot 10^{-1}$ \\
\hline Glass BK-7 & 1.039612 & $2.317923 \cdot 10^{-1}$ & 1.010169 \\
\hline
\end{tabular}

Table 2

Selmeier coefficients $C_{i}$ in the dispersion formula (16)

\begin{tabular}{|l|c|c|c|}
\hline $\begin{array}{c}\text { Optical } \\
\text { material }\end{array}$ & $\mathrm{C}_{1,} \mu \mathrm{m}^{2}$ & $\mathrm{C}_{2,} \mu \mathrm{m}^{2}$ & $\mathrm{C}_{3}, \mu \mathrm{m}^{2}$ \\
\hline Quartz & $4.480112 \cdot 10^{-3}$ & $1.328170 \cdot 10^{-2}$ & 95.341482 \\
\hline Glass BK-7 & $6.000698 \cdot 10^{-3}$ & $2.001791 \cdot 10^{-2}$ & 103.560653 \\
\hline
\end{tabular}

\section{RESULTS AND ITS DISCUSSION}

The calculations of the propagation of pulses through optical materials in the second approximation of the theory of dispersion, presented in Tables 3, 4 and in Figs. 1, 2 showed that the elongation of the pulses of both profiles is greater, the shorter their initial duration. So from Table 3 and Fig. 1 it is clear that pulses with a Gaussian profile (5) and a duration of $30 \mathrm{fs}$ when passing through $43 \mathrm{~mm}$ of quartz are elongated by 4.78 times, and when passing through a BK-7 glass of the same length, they are elongated by 5.85 times. Pulses with the same profile and a duration of $100 \mathrm{fs}$ when passing through quartz and BK-7 glass of the same length are elongated 1.09 and 1.13 times, respectively.

Table 3

The duration of pulses with a Gaussian profile (5) after passing the distance $\ell$ through quartz and BK-7 glass in

the second approximation of dispersion theory

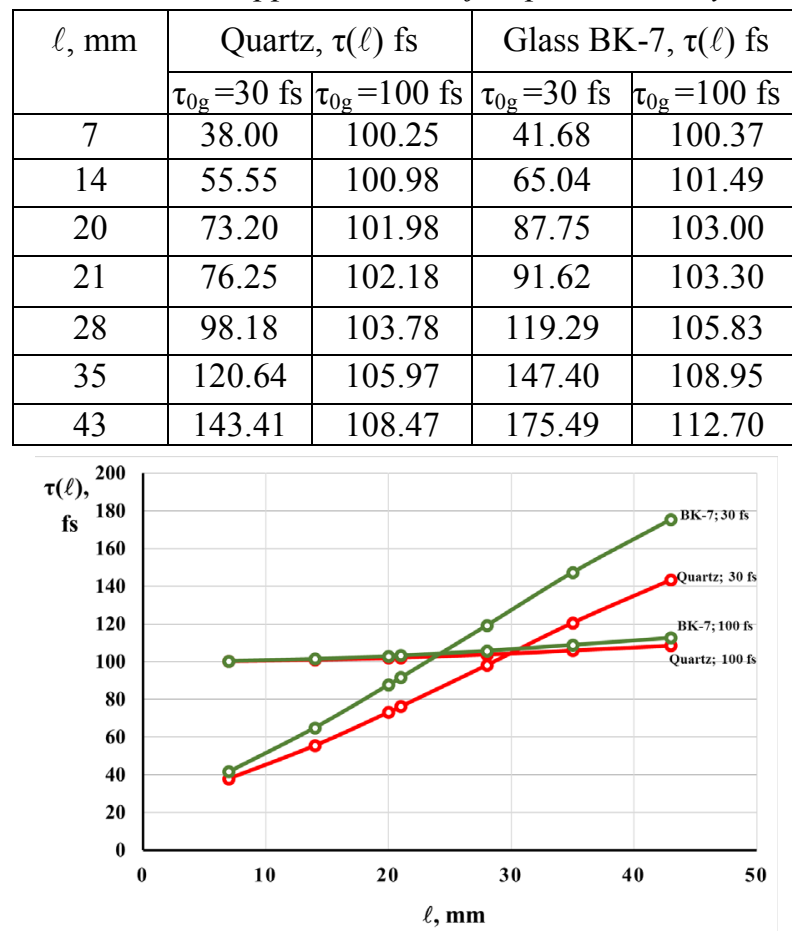

Fig. 1. Dependence of the pulse duration with a Gaussian profile on the length of the optical medium in the second approximation of dispersion theory 
Table 4

The duration of pulses with a profile proportional to the hyperbolic secant (6) after passing the distance $\ell$ through quartz and BK-7 glass in the second approximation of dispersion theory

\begin{tabular}{|c|c|c|c|c|}
\hline \multirow{2}{*}{$\ell, \mathrm{mm}$} & \multicolumn{2}{|c|}{ Quartz, $\tau(\ell) \mathrm{fs}$} & \multicolumn{2}{c|}{ Glass BK-7, $\tau(\ell) \mathrm{fs}$} \\
\cline { 2 - 5 } & $\tau_{0 \mathrm{~s}}=30 \mathrm{fs}$ & $\tau_{0 \mathrm{~s}}=100 \mathrm{fs}$ & $\tau_{0 \mathrm{~s}}=30 \mathrm{fs}$ & $\tau_{0 \mathrm{~s}}=100 \mathrm{fs}$ \\
\hline 7 & 43.28 & 100.64 & 47.18 & 101.15 \\
\hline 14 & 59.50 & 103.16 & 66.64 & 104.87 \\
\hline 20 & 72.82 & 106.15 & 83.08 & 109.85 \\
\hline 21 & 74.87 & 106.66 & 85.84 & 109.49 \\
\hline 28 & 90.25 & 110.90 & 104.10 & 115.13 \\
\hline 35 & 104.20 & 115.38 & 122.56 & 121.15 \\
\hline 43 & 120.00 & 120.26 & 142.05 & 127.31 \\
\hline
\end{tabular}

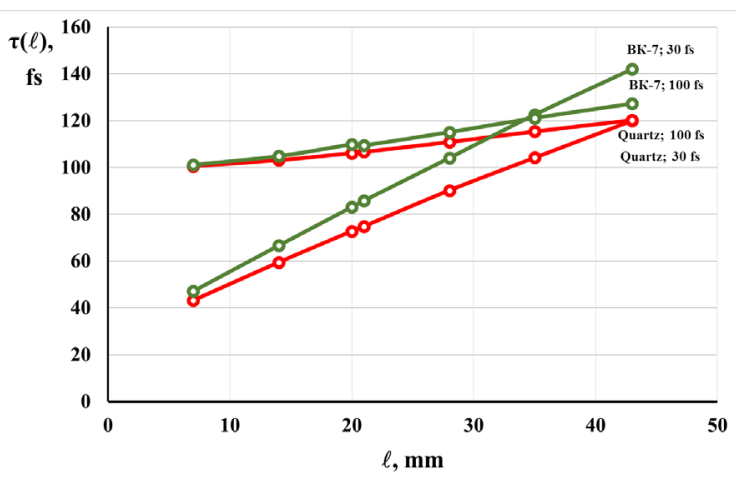

Fig. 2. Dependence of the pulse duration with a profile proportional to to the hyperbolic secant (eq. (6)) on the length of the optical medium in the second approximation of dispersion theory

Similar calculations according to the data in Table 3 and Fig. 2 showed that pulses with a profile proportional to the hyperbolic secant (6) and a duration of $30 \mathrm{fs}$ when passing through $43 \mathrm{~mm}$ of quartz are elongated by 4 times, and when passing through a BK-7 glass of the same length are elongated 4.74 times. Pulses with the same profile and a duration of 100 fs when passing through quartz and BK-7 glass of the same length are elongated by 1.20 and 1.27 times, respectively.

The calculations of the pulse propagation in the fourth approximation of the dispersion theory presented in Tables 5, 6 and in Figs. 3,4 in comparison with similar calculations in the second approximation of the dispersion theory showed that taking into account the third and fourth derivatives of the phase in frequency in solution (12) slightly increases the values of their duration after passing through optical material. So, when calculating the propagation of $30 \mathrm{fs}$ pulses with a Gaussian profile (5) through quartz, the fourth approximation of the dispersion theory gives an increase in the duration for the lengths from the tables within $(0.46 \ldots 4.68)$ fs [or $(0.73 \ldots 3.26) \%$ ] compared with the second approximation. Similar calculations for pulses with the same initial profile and a duration of 100 fs give an increase in the range of $(0.82 \ldots 1.75)$ fs [or $(0.80 \ldots 1.75) \%$ ]. As can be seen from Table 5 and Fig. 3, pulses with a Gaussian profile (5) and a duration of $30 \mathrm{fs}$ when passing through $43 \mathrm{~mm}$ of quartz are elongated 4.94 times versus 4.78 times in the second approximation. Pulses with the same profile and a duration of $100 \mathrm{fs}$ are elongated 1.10 times versus 1.09 in the second approximation.
Table 5

Duration of pulses with a Gaussian profile (5) after passing the distance $\ell$ through quartz and BK-7 glass in the fourth approximation of dispersion theory

\begin{tabular}{|c|c|c|c|c|}
\hline \multirow{2}{*}{$\ell, \mathrm{mm}$} & \multicolumn{2}{|c|}{ Quartz, $\tau(\ell) \mathrm{fs}$} & \multicolumn{2}{c|}{ Glass BK-7, $\tau(\ell) \mathrm{fs}$} \\
\cline { 2 - 5 } & $\tau_{0 \mathrm{~g}}=30 \mathrm{fs}$ & $\tau_{0 \mathrm{~g}}=100 \mathrm{fs}$ & $\tau_{0 \mathrm{~g}}=30 \mathrm{fs}$ & $\tau_{0 \mathrm{~g}}=100 \mathrm{fs}$ \\
\hline 7 & 38.46 & 102.00 & 41.82 & 102.00 \\
\hline 14 & 56.08 & 102.00 & 66.36 & 102.00 \\
\hline 20 & 73.77 & 103.00 & 88.53 & 104.00 \\
\hline 21 & 76.92 & 103.00 & 92.06 & 104.00 \\
\hline 28 & 99.22 & 105.02 & 120.00 & 107.08 \\
\hline 35 & 121.53 & 107.20 & 147.64 & 110.10 \\
\hline 43 & 148.09 & 110.20 & 181.77 & 114.10 \\
\hline
\end{tabular}

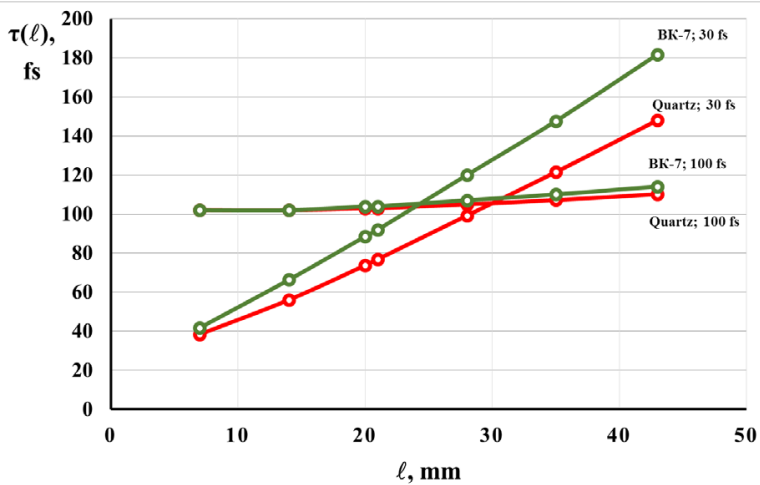

Fig. 3 Dependence of the pulse duration with a Gaussian profile on the length of the optical medium in the fourth approximation of dispersion theory

Table 6

The duration of pulses with a profile proportional to the hyperbolic secant (6) after passing the distance $\ell$ through quartz and BK-7 glass in the fourth approximation of dispersion theory

\begin{tabular}{|c|c|c|c|c|}
\hline \multirow{2}{*}{$\begin{array}{c}\ell, \\
\mathrm{mm}\end{array}$} & \multicolumn{2}{|c|}{ Quartz, $\tau(\ell) \mathrm{fs}$} & \multicolumn{2}{c|}{ Glass BK-7, $\tau(\ell) \mathrm{fs}$} \\
\cline { 2 - 5 } & $\tau_{0 \mathrm{~s}}=30 \mathrm{fs}$ & $\tau_{0 \mathrm{~s}}=100 \mathrm{fs}$ & $\tau_{0 \mathrm{~s}}=30 \mathrm{fs}$ & $\tau_{0 \mathrm{~s}}=100 \mathrm{fs}$ \\
\hline 7 & 45.00 & 102.00 & 48.00 & 102.00 \\
\hline 14 & 60.00 & 104.00 & 68.00 & 106.00 \\
\hline 20 & 74.50 & 107.10 & 84.00 & 110.00 \\
\hline 21 & 76.00 & 108.00 & 86.72 & 110.10 \\
\hline 28 & 91.00 & 112.00 & 105.33 & 116.80 \\
\hline 35 & 107.50 & 116.00 & 123.00 & 122.80 \\
\hline 43 & 124.50 & 122.00 & 146.00 & 129.40 \\
\hline
\end{tabular}

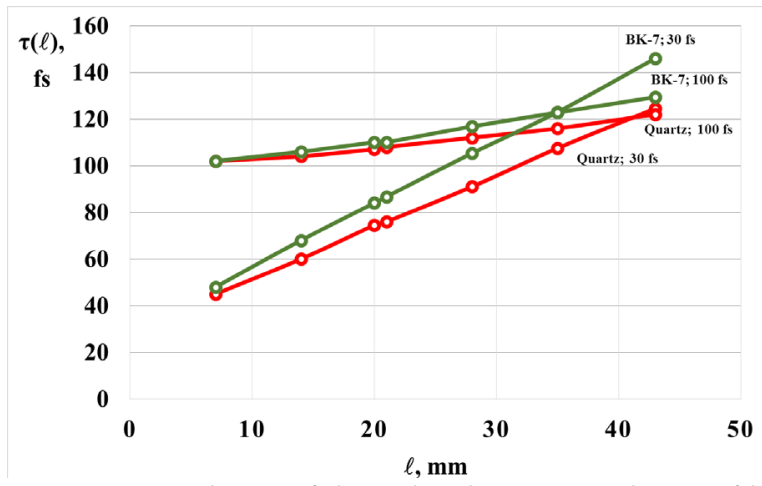

Fig. 4. Dependence of the pulse duration with a profile proportional to the hyperbolic secant on the length of the optical medium in the fourth approximation of dispersion theory

When calculating the propagation of 30 fs pulses with a profile proportional to the hyperbolic secant (6) 
through quartz, the fourth approximation of the dispersion theory gives an increase in the duration for the lengths from the tables within $(0.50 \ldots 4.5)$ fs [or $(0.84 \ldots 3.97) \%$ ] compared with the second approximation. Similar calculations for pulses with the same profile and a duration of $100 \mathrm{fs}$ give an increase in the range of $(0.62 \ldots 1.85)$ fs [or $(0.54 \ldots 1.45) \%$ ]. The calculations performed according to the data of Table 6 and Fig. 4 showed that pulses with a profile proportional to the hyperbolic secant (6) and a duration of $30 \mathrm{fs}$ when passing through $43 \mathrm{~mm}$ of quartz are elongated 4.15 times versus 4 times in the second approximation. Pulses with this profile and a duration of $100 \mathrm{fs}$, when passing through quartz of the same length, they are 1.22 times longer than 1.20 in the second approximation.

When calculating the propagation of $30 \mathrm{fs}$ pulses through the BK-7 glass with a Gaussian profile (5) the fourth approximation of the dispersion theory gives an increase in the duration within $(0.14 \ldots 6.28)$ fs [or $(0.16 \ldots 3.58) \%$ ] compared with the second approximation. Similar calculations for pulses with the same profile and a duration of $100 \mathrm{fs}$ give an increase in the range of $(0.51 \ldots 1.40)$ fs [or $(0.50 \ldots 1.62) \%\}$. The calculations carried out according to the data in Table 5 and Fig. 3 showed that, the $30 \mathrm{fs}$ pulses with a Gaussian profile after passing through a BK-7 glass of 43-mmlong are 6.06 times longer compared to 5.85 in the second approximation. Pulses with the same profile and the duration of $100 \mathrm{fs}$, when passing through a BK-7 glass of the same length, they are elongated 1.14 times versus 1.13 in the second approximation.

When calculating the propagation through the glass of BK-7 of pulses with a profile proportional to the hyperbolic secant (6) and a duration of $30 \mathrm{fs}$, the fourth approximation of the dispersion theory gives an increase in the duration for the lengths [see Tables 4, 6] within $(0.44 \ldots 3.95)$ fs [or $(0.36 \ldots 2.78) \%$ ] compared to the second approximation. Similar calculations for pulses with the same initial profile and a duration of $100 \mathrm{fs}$ give an increase in the range of $(0.15 \ldots 2.09)$ fs [or $(0.14 \ldots 1.64) \%]$. Calculations conducted according to the data of Table 6 and Fig. 4, showed that the 30 fs pulses with a profile proportional to hyperbolic secant (6) when passing through the $43 \mathrm{~mm}$ glass BK-7 are extended 4.87 times against 4.74 times in the second approximation. Pulses with the same profile and a duration of $100 \mathrm{fs}$ when passing through a BK-7 glass of the same length are elongated 1.29 times versus 1.27 in the second approximation.

It should be remembered that there may exist optical materials in which the third and fourth derivative phases in frequency have large values, and their influence on the results of calculation of pulse length can be significant. Therefore, the problem of the propagation of pulses through optical materials should be solved both in the second and fourth approximations of the theory of dispersion. Comparing the results obtained, it is necessary to evaluate the effect on them of taking into account the above additional phase derivatives in frequency.

The comparison of the corresponding graphs of the pulse elongation of different profiles constructed in both the second and fourth approximations of the dispersion theory shows that for both optical materials $\sim 19 \mathrm{~mm}$ in length, the pulse durations of both profiles are the same. For quartz, it is $\sim 70.4 \mathrm{fs}$ in the second approximation and $\sim 72.9 \mathrm{fs}$ in the fourth approximation, for BK-7 glass it is $82.2 \mathrm{fs}$ in the second approximation and $\sim 84.2 \mathrm{fs}$ in the fourth approximation. For optical materials shorter than $19 \mathrm{~mm}$, the pulse duration with a Gaussian profile is shorter than that for pulses with a profile proportional to the hyperbolic secant, and with a length of more than $19 \mathrm{~mm}$, the pulse duration with a Gaussian profile exceeds that for pulses with a Gaussian profile proportional to the hyperbolic secant. As for pulses with a duration of $100 \mathrm{fs}$, with an increase in the length of both materials, the elongation of pulses with a profile proportional to the hyperbolic secant grows faster than pulses of a Gaussian profile.

\section{CONCLUSIONS}

Based on the solutions of the shortened wave equations in the second and fourth approximations of the dispersion theory, which describe the propagation of pulses through quartz and BK-7 glass, the dependences of the pulse elongation of the Gaussian profile and the profile proportional to the hyperbolic secant on the length of the optical material are obtained. They allow to choose the pulse of the desired profile and the material of the desired length to obtain a pulse of a given duration. The described technique can be applied to solving problems of pulse propagation having a known initial profile through any optical materials with known dependences of the refractive index on the wavelength.

\section{ACKNOWLEDGEMENT}

Work was partially supported by the Ukrainian budget program "Support for the most important directions of scientific researches" (КПКВК 6541230).

\section{REFERENCES}

1. G.A. Mourou. Optics in the relativistic regime // Reviews of modern physics. 2006, v. 78, April-June, p. 309-371.

2. V.A. Balakirev, I.N. Onishchenko. Cherenkov radiation of a laser pulse in ion dielectrics // Problems of Atomic Science and Technology. Series "Plasma Electronic and New Methods of Acceleration". 2019, № 4, p. 39-47.

3. V.I. Maslov, D.S. Bondar, I.N. Onishchenko, V.G. Papkovich. Effect of Transition Radiation and Dispersion Spreading at Achievement of a Large Transformer Ratio of Exciting Bunch Energy into Wakefield in a Dielectric Resonator Accelerator // Problems of Atomic Science and Technology. 2019, № 4, p. 48-54.

4. M. Rosete-Aguilar, F.C. Estrada-Silva, N.C. Bruce, C.J. Roman-Moreno, and R. Ortega-Martinez. Calculation of temporal spreading of ultrashort pulses propagating through optical glasses // Revista Mexicana de Fisica. 2008, v. 54, № 2, p. 141-148.

5. I. Herman, B. Wilhelmy. Ultrashort pulse lasers. M.: "Mir", 1986, p. 95.

6. S.A. Akhmanov, Yu.E. Dyakov, A.S. Chirkin. Introduction to statistical radiophysics and optics. M.: "Nauka", 1981, p. 271-277 (in Russian). 
7. V.P. Leshchenko, A.I. Povrozin, S.Y. Karelin. Calculation of Stretching Factor for Optical Pulse Stretcher // Problems of Atomic Science and Tech- nology. Series "Nuclear Physics Investigations". 2014, № 3, p. 214-217.

Article received 04.10.2019

\section{ПРОХОЖДЕНИЕ ОПТИЧЕСКИХ ФЕМТОСЕКУНДНЫХ ИМПУЛЬСОВ ЧЕРЕЗ КВАРЦ И СТЕКЛО ВК-7}

\section{В.П. Лещенко, А.И. Поврозин, Г.В. Сотников, А.В. Васильев, К.В. Галайдыч, С.Ю. Карелин}

Теоретически исследовано прохождение оптических фемтосекундных импульсов гауссового профиля и профиля, пропорционального гиперболическому секансу, через кварц и стекло ВК-7 в приближении теории дисперсии до четвёртого порядка включительно. На основании решений уравнений прохождения импульсов различной начальной длительности через оптические материалы построены графики зависимостей «длина материала - длительность импульса». Показано, что по сравнению со вторым приближением теории дисперсии четвёртое приближение незначительно влияет на зависимость длительности импульсов от длины оптического материала. Также показаны особенности влияния дисперсии оптических материалов на длительность импульсов различных временных профилей. Аналитическое рассмотрение подтверждено численными расчётами.

\section{ПРОХОДЖЕННЯ ОПТИЧНИХ ФЕМТОСЕКУНДНИХ ІМПУЛЬСІВ ЧЕРЕЗ КВАРЦ ТА СКЛО ВК-7}

\section{В.П. Лещенко, А.І. Поврозін, Г.В. Сотніков, А.В. Васильєв, К.В. Галайдич, С.Ю. Карелін}

Теоретично досліджено проходження оптичних фемтосекундних імпульсів гаусового профіля та профіля, пропорційного гіперболічному секансу, через кварц та скло ВК-7 у наближенні теорії дисперсії до четвертого порядка включно. На основі рішень рівнянь проходження імпульсів різної початкової тривалості через оптичні матеріали побудовано графіки залежностей «довжина матеріалу - тривалість імпульсу». Показано, що в порівнянні з другим наближенням теорії дисперсії четверте наближення незначно впливає на залежність тривалості імпульсів від довжини оптичного матеріалу. Також показано особливості впливу дисперсії оптичних материіалів на тривалість імпульсів різних часових профілей. Аналітичний розгляд підтверджено чисельними розрахунками. 